\title{
IMAGEM E VISIBILIDADE NA NARRATIVA DE PETER HANDKE
}

\author{
André Soares Vieira \\ Universidade Federal de Santa Maria
}

\begin{abstract}
RESUMO
O presente trabalho tem por objetivo mapear algumas das categorias provenientes do imaginário visual contemporâneo, sobretudo o cinematográfico, absorvidas e representadas pelo texto literário, em uma cultura marcada pelo apelo às imagens industriais. Toma-se como base de análise o texto Breve carta para um longo adeus, do austríaco Peter Handke.
\end{abstract}

\section{PALAVRAS - CHAVE}

Ficção contemporânea, cultura midiática, imaginário cinematográfico, visualidade

\begin{abstract}
Ainda que a questão da adaptação de obras literárias domine os estudos comparatistas entre o romance e o cinema, numerosos têm sido os trabalhos que testemunham a presença da Sétima Arte no imaginário dos escritores. Jacqueline Viswanathan ${ }^{1}$, em um seminal artigo sobre o imaginário do cinema no romance quebequense, distingue duas abordagens diferentes quanto ao estudo de tais relações. A primeira abordagem interessar-se-ia, prioritariamente, pelos modos de apresentação e pelas técnicas narrativas romanescas, por meio de uma comparação com as características da imagem e da narrativa fílmicas. O interesse maior desse tipo de abordagem residiria na tentativa de mostrar sob que formas novos procedimentos narrativos haviam respondido ao modo de percepção do universo criado pelas recentes tecnologias da imagem. A preocupação maior diria respeito ao mapeamento de aspectos fílmicos da narração, presentes em numerosos romances contemporâneos: decupagem da diegese, novos modos de focalização, segmentação da narrativa, montagem e enquadramento. Nesse tipo de abordagem, cumpre notar que, em nenhum dos romances analisados, o cinema integra explicitamente a diegese. Cabe ao crítico desvendar, de modo mais ou menos convincente, uma possível influência manifestada de forma indireta no âmbito da narração e não em sua temática.

A segunda abordagem partiria do princípio de que as novas tecnologias da imagem foram assimiladas pelo imaginário contemporâneo e que a literatura representaria o lugar privilegiado para testemunhar as conseqüências desse fenômeno. O cinema, nesse sentido, seria visto, segundo Jeanne-Marie Clerc, como elemento desencadeador de novas perspectivas de apreensão do mundo e responsável por um processo de profunda
\end{abstract}

${ }^{1}$ VISWANATHAN. L'imaginaire do cinéma dans trois romans québécois, p. 135. 
modificação no modo como o homem se situa perante o universo e descreve suas relações com o real e com o imaginário.

Para Clerc, ao introduzir o maquinário óptico no seio mesmo da organização racional do espaço vitruviano, o homem barroco acabou por fazer oscilar esse espaço para além dos limites da razão. No entanto, as vertigens proporcionadas pelas mises-en-abîme estavam asseguradas, aos olhos do espectador do teatro barroco, por uma ordem cultural que discernia claramente os limites entre a realidade ilusória e a realidade metafísica de que não se duvidava. Por trás da ilusão, imperava um universo estável e seguro, capaz de dissipar a angústia causada pelos reflexos de trompe-l'oeil vertiginosos. Para o homem moderno, tal referência inconteste deixa de existir, mantendo o sujeito à deriva, em uma eterna confusão entre o real, o imaginário e seus simulacros. ${ }^{2}$

Por sua vez, no romance realista, o visual adquire a função de motivar a descrição, identificando-se com um desejo pedagógico de transmitir informações sobre o real. Através da descrição, o autor realista pode difundir seu saber enciclopédico, incorporando-o com verossimilhança à ficção. Assim, o olhar da personagem, as referências a ilustrações, aos espetáculos e às artes visuais não somente garantem a informação como caucionam o efeito do real.

As bases do edifício romanesco arquitetado por Balzac começam a ruir a partir dos experimentos do romance moderno que, entre outros aspectos, passa a incorporar os efeitos visuais da descrição, de forma aparentemente mais livre das motivações realistas. Também as categorias de espaço-tempo perdem as dimensões até então fixadas: o tempo se espacializa e o espaço é temporalizado, criando-se uma espécie de lógica intersticial da narrativa, que passa a representar um estado intervalar entre o verdadeiro e o falso, o possível e o impossível.

Por volta da segunda metade do século XX, as imagens industriais impõem-se como mediação entre o indivíduo e o real: o mundo já não mais se apresenta em estado puro, pronto para ser apropriado pelo homem, mas antes como instância que deve ser representada, reproduzida ou editada pelos meios de comunicação. O romance traduzirá essa nova ordem apresentando personagens à deriva, em um mundo caótico e sem sentido aparente, interessadas apenas na percepção subjetiva que têm desse mundo, obrigadas a "ler" a realidade através de signos, placas, imagens televisivas ou cinematográficas, fotografias, etc.

Breve carta para um longo adeus (Der kurze Brief zum langen Abschied) foi publicado em 1972 pelo austríaco Peter Handke, cuja trajetória é permeada pela produção literária, teatral e cinematográfica. Colaborou como roteirista de Wim Wenders em filmes como Asas do desejo e Falso movimento. Teve seu romance $O$ medo do goleiro na hora do pênalti adaptado para o cinema por Wenders e dirigiu, ele próprio, A mulher canhota, adaptado de sua obra homônima. Passeou, portanto, com igual desenvoltura, pelas diversas mídias a exemplo de tantos outros contemporâneos - Marguerite Duras, Alain Robbe-Grillet, Pier Paolo Pasolini - captando com maestria a solidão do homem moderno perdido em um mundo saturado de imagens.

Em Breve carta, Handke apresenta um narrador-protagonista em uma viagem pela América, atravessando desertos, lugares inóspitos e vazios, vagamente motivado pela busca de sua esposa. Impossibilitado de realizar uma viagem de caráter iniciático que o

${ }^{2}$ CLERC. A literatura comparada frente às imagens modernas: cinema, fotografia, televisão, p. 318-319. 
faça compreender a si próprio e ao mundo que o cerca, é tomado, conforme observou César Guimarães, pela perambulação, pela errância e pela deriva.

O livro compõe-se de duas partes. A primeira, intitulada A breve carta, mistura impressões sobre a América, onde o narrador acaba de chegar, a lembranças da infância - o medo frente aos bombardeiros americanos durante a guerra, alguém a quem amara e que desaparecera na floresta, a busca pela mãe, quando essa desaparece, seu encontro nos rochedos, as primeiras leituras, seu nascente fascínio pelas imagens do texto - além de relatos de pequenos acontecimentos relativos à vida na América, a leitura de Grüne Heinrich, de Gottfried Keller, e suas idas ao cinema.

A segunda parte do romance, A longa despedida, concentra-se na viagem de carro realizada pelo narrador em companhia de uma amiga, Claire, e de sua filha de dois anos, Benedictine. Durante a viagem, visitam um casal americano de pintores, o "casal de amantes", que apenas pinta paisagens históricas da América e, finalmente, acabam indo ao encontro do cineasta John Ford. A narrativa inclui ainda lembranças da esposa desaparecida, Judith, entremeadas às experiências vividas nos Estados Unidos.

A viagem é aqui responsável pelo acionamento da memória, como o fora o cinema na primeira parte do romance. A América se dá a conhecer em suas paisagens desertas, em suas cidades, nas representações que os americanos fazem de sua história e nas próprias histórias contadas pelo cinema hollywoodiano.

Ao longo da viagem, o narrador percebe que é dotado de uma espécie de memória ativa, capaz de assegurar uma maior compreensão do mundo:

- Só agora descobri em mim algo como uma memória ativa [...] Antes só tinha uma memória sofredora. Manejando a memória, porém, não quero repetir as experiências inteiras, apenas não permitir que as primeiras pequenas esperanças que senti com elas encolham e se transformem em devaneios. ${ }^{3}$

Anestesiado pelo bombardeio incessante de imagens e signos que caracterizam a América e, por extensão, o mundo ocidental contemporâneo, o narrador de Breve carta para um longo adeus não apreende a realidade como o fizeram os heróis de Goethe, por exemplo, ao contemplarem a paisagem da natureza. A viagem empreendida pelo narrador não mais representa uma forma de aprendizagem para a compreensão do mundo, já não há devir possível, nem possibilidade de se tornar uma pessoa melhor. As cidades, os carros e os anúncios luminosos substituíram a natureza romântica e o herói moderno já não mais progride rumo a um conhecimento de si e do mundo. $O$ narrador de Breve carta anestesia-se com a realidade circundante, repleta de signos e imagens, e acaba por compreender o mundo através de sua experiência, esta, sim, capaz de fornecer uma aprendizagem, ao ativar os fragmentos da memória.

Em um certo sentido, a Breve carta de Handke responde à pergunta lançada por Italo Calvino em Seis propostas para o próximo milênio. Na quarta proposta, dedicada à Visibilidade, Calvino questiona se o poder de evocação de imagens in absentia continuaria a desenvolverse em uma humanidade cada vez mais inundada pelo dilúvio das imagens pré-fabricadas. No passado, a memória visiva de um indivíduo restringia-se ao patrimônio de suas experiências

${ }^{3}$ HANDKE. Breve carta para um longo adeus, p. 121. 
diretas e a um reduzido repertório de imagens refletidas pela cultura; a possibilidade de dar formas a mitos pessoais nascia do modo pelo qual os fragmentos dessa memória se combinavam entre si. Hoje somos bombardeados por uma tal quantidade de imagens a ponto de não podermos distinguir mais a experiência direta daquilo que vimos há poucos segundos na televisão: "Em nossa memória se depositam, por estratos sucessivos, mil estilhaços de imagens, semelhantes a um depósito de lixo, onde é cada vez menos provável que uma delas adquira relevo." ${ }^{4}$

Também na memória do narrador-protagonista de Breve carta para um longo adeus, depositam-se milhares de imagens fragmentadas que vêm à tona em sua viagem pela América. Ao final da narrativa, no entanto, acaba conferindo um novo valor ao olhar e à memória, tendo percebido ser ainda possível extrair alguma aprendizagem desse visível que nos sufoca.

Para César Guimarães, Handke se empenha em construir uma espécie de romance de aprendizagem da era das imagens:

A diferença é que, aqui, em vez da natureza e dos lugares penetrados pelo tempo histórico, dos quais era possível extrair uma aprendizagem, agora o narrador deve voltar-se para um conjunto de imagens e de signos que resguardam, precariamente, os traços da história seja aquela dos lugares que ele percorre, seja a sua própria história, remanescente em fragmentos e episódios dispersos na memória [...] a viagem pela América torna-se um meio que possibilita ao protagonista reelaborar sua relação com as imagens da memória e com a experiência que elas resguardam..$^{5}$

Ao distinguir três etapas da teoria da visão no século XX, Fredric Jameson elege a última como sendo a da sociedade da imagem, iniciada por volta da década de 80 e coincidindo com o processo de sistematização da cultura pós-moderna. Nesse momento, os sujeitos humanos, já expostos ao bombardeio de até mil imagens por dia, vivem e consomem cultura de maneiras novas e diferentes, a reflexividade se submerge na superabundância de imagens tornada natural. Essa nova situação, propriamente pósmoderna, significa uma maior estetização da realidade "que é também, ao mesmo tempo, uma visualização ou colocação em imagens mais completa dessa mesma realidade". ${ }^{6}$

Em Breve carta, o convívio diário com a proliferação de imagens acaba por anestesiar o indivíduo tanto para as imagens visuais quanto para as sonoras, fazendo com que empobreçam de significações e deixem os sentidos insensibilizados. A memória surge como matéria-prima, assim como o cinema, da literatura, em resposta ao perigo dos desligamentos de nossos sentidos: a memória como todo um rol de imagens diferentes - retratos, fotografias, quadros, descrições, cenas; ou seja, conjuntos de signos a compor conjuntos de imagens, ilusões e sonhos que passam a fazer parte da memória individual e coletiva.

O sujeito, nessa perspectiva, aparece como ser atordoado pela variedade sígnica e pela velocidade da civilização da imagem, podendo levá-lo à total incomunicabilidade e isolamento. A paisagem que é oferecida aos olhos do narrador de Handke em nada se assemelha à natureza da qual a personagem de Goethe se apodera, dela tornando-se mestre. No entanto, conforme sublinhou Guimarães, este novo regime do visível ainda

\footnotetext{
${ }^{4}$ CALVINO. Seis propostas para o próximo milênio, p. 107.

${ }^{5}$ GUIMARÃES. Imagens da memória, p. 153.

${ }^{6}$ JAMESON. Espaço e imagem, p. 120.
} 
pode ser lido enquanto conjunto de signos e de símbolos, por meio de imagens, gestos, costumes, modos de comportamento, traços históricos e imagens do cinema. Ao narrador de Breve carta resta compreender o mundo através da leitura da realidade mediatizada pelas imagens e signos urbanos.

Quando estive aqui pela primeira vez, só queria ver imagens [...] Postos de gasolina, táxis amarelos, autocines, propagandas, auto-estradas, os ônibus Greyhound, uma placa de BUS STOP na estrada federal, o trem de Santa Fé, o deserto. Tinha uma consciência despovoada de gente, e sentia-me bem assim. Agora estou farto de todas essas imagens, e quero ver outra coisa, mas também mais raramente me sinto bem, porque as pessoas aqui são sempre novas demais para mim. ${ }^{7}$

A preocupação com a memória faz com que o narrador fotografe a menina, filha de Claire, durante a viagem, acreditando, assim, que a imagem fixa possa registrar um estado que, logo em seguida, seria para sempre perdido:

Além disso, eu acreditava que, fotografando, podia deixar com a criança imagens para serem lembradas mais tarde, e imaginava dessa maneira aparecer alguma coisa na memória da criança. Com a mesma intenção, certa vez rodei com ela de ônibus por St. Louis, e fiquei longo tempo parado na margem do Mississipi; o cheiro da água talvez ajudasse a memória. (p. 146)

Em um mundo saturado de imagens, o narrador aprende a contemplar os acontecimentos, nova conquista para um indivíduo até então insulado em seu mundo, preso à velocidade da informação, ao zapping, ao olhar que não consegue selecionar a imagem e, muito menos, detê-la por uma fração de segundo para admirá-la e, então, nomeá-la de forma reflexiva.

Quando eu estava com a criança, e a toda hora ela me perguntava os nomes das coisas, notei o quanto até ali me preocupara exclusivamente comigo mesmo, pois muitas das coisas que nos rodeavam eu nem sabia o que eram. Só então notei que me faltavam palavras para os movimentos mais comuns ao meu redor. Assim, aprendi aos poucos a contemplar os acontecimentos até o fim, em vez de apenas olhar e dizer "ah!” (p. 147)

Do mesmo modo, percebe que a criança sente-se mais à vontade diante dos signos e imagens da civilização, como se fossem próprios da natureza, do que em relação à verdadeira natureza, esta representando uma fonte de inquietação e angústia para ambos:

Era singular que Benedictine quase não prestasse mais atenção à natureza, mas já experimentasse os sinais e objetos artificiais da civilização como natureza. Perguntava muito antes sobre antenas de tevê, faixas de pedestre no asfalto e sirenes de polícia, do que sobre florestas e relvas, e parecia ficar mais animada e ao mesmo tempo mais calma rodeada de sinais, inscrições luminosas e lampiões. Assim, ela considerava sinais e números coisas da natureza contemplado-os como coisas óbvias sem ter de primeiro decifrá-los como sinais. E notei que também eu me entediava muito quando uma paisagem me parecia pura natureza, e não havia nada nela para ler. (p. 147)

Confirmando a tese benjaminiana acerca da reprodutibilidade técnica das obras de arte, Benedictine despreza a origem ou o modelo e encara as reproduções e sinais como coisas em-si:

\footnotetext{
${ }^{7}$ HANDKE. Breve carta para um longo adeus, p. 123. Todas as demais citações deste livro virão seguidas do número da página na qual se encontram
} 
Quando a criança via algo que imitava a verdadeira natureza, por exemplo algum quadro do pintor, absolutamente não lhe interessava onde e nem se havia modelo para aquilo, pois a reprodução o substituíra para sempre. E lembrei-me de novo de que, em contrapartida, quando criança eu sempre tinha querido saber onde as coisas representadas existiam na realidade. (p. 147)

Segundo Benjamin, a autenticidade da obra de arte está baseada em seu aqui e agora irreprodutível pela técnica. Se a reprodução manual é vista como uma falsificação em relação à obra autêntica, o mesmo não pode ser afirmado sobre a técnica, e isso se deve a dois motivos. Em primeiro lugar, por sua maior autonomia em relação ao original, podendo assim ressaltar aspectos originais da obra autêntica não captáveis pelo olho humano; em segundo lugar, por sua possibilidade de transpor a obra de arte para locais antes inimagináveis. Na reprodução técnica industrial, a obra é multiplicada por conta da produção em série, não mais pertencendo à tradição, mas tendo sua aura atrofiada.

Os quadros do pintor americano, enquanto reproduções manuais, configuram-se, assim, como representações simuladas de uma realidade, de uma natureza histórica americana, necessária para a compreensão do sentido de toda uma civilização. Nessa perspectiva, o cinema, ainda segundo Benjamin, representaria um dos agentes responsáveis pelo abalo de toda uma tradição fundada na autenticidade (o aqui e agora) da obra de arte. Aqui e agora que, na contemporaneidade, cede lugar à tecnologia "tele" ou "digital".

\section{O IMAGINÁRIO DO CINEMA}

É em meio a esse mundo saturado de imagens que a literatura irá solicitar ao cinema aquilo que Deleuze identificou como uma de suas principais qualidades: o fato de não apenas apresentar imagens, mas de cercá-las com mundos possíveis e diversos.

A literatura de Handke apresenta-se como uma literatura do detalhe, do gesto ínfimo e anódino, aparentemente insignificante, das miudezas do cotidiano, da apreensão do mundo pela percepção fenomenológica das pequenas ações. A exemplo de Flaubert, seu mestre confesso, Handke evita as descrições dos estados de alma de suas personagens ou os comentários acerca dos progressos de suas emoções. Prefere, antes, a enumeração dos gestos e pequenos atos cotidianos, infinitamente mais ricos e imagéticos, para a construção de uma estética do detalhe. A verdade do ser humano é encontrada por trás dos gestos miúdos e pelas alterações de seus hábitos. A definição da essência das personagens advém do modo como elas se movem, agem, caminham; suas mudanças comportamentais podem se originar da simples forma de pisar de modo mais firme ou de falar com maior desenvoltura.

Nessa visão obcecada pelo detalhe, que estende a frase e segmenta as ações, percebese a presença do cinema no texto de Handke. Ainda como Flaubert, cuja obra é freqüentemente caracterizada como pré-cinematográfica, ao apresentar ações simultâneas e fragmentadas entre si na criação de um todo coeso, Handke opta por uma linguagem ascética e, ao mesmo tempo, obsessiva, ao relatar uma série de acontecimentos e gestos diários que traduzirão as mudanças no estado das personagens.

Sentia-me outra vez como antigamente quando durante algum tempo, ao descrever para alguém o que acabara de fazer, não conseguia deixar de fora nenhum dos detalhes que constituíam o todo. Se entrava numa casa, em vez de dizer "Entrei na casa", dizia "Limpei 
os sapatos, baixei a maçaneta, abri a porta e entrei, depois fechei a porta atrás de mim”. E quando mandava uma carta a outra pessoa, sempre (em vez de: "Mandei a carta"), eu "colocava a folha de papel limpa sobre uma base, tirava a tampa da caneta, escrevia na folha, dobrava-a, metia-a num envelope, sobrescritava o envelope, colocava um selo em cima, e jogava a carta na caixa”. (p. 93)

Trata-se, aqui, do próprio autor explicando seu método de criação. A falta de conhecimentos e experiências do narrador-protagonista de Breve carta para um longo adeus cria a ilusão, "fragmentando de tal maneira em detalhes as poucas ações que conseguia executar, como se falasse de grandes experiências" (p. 93). Heróis da contemporaneidade, perdidos em um universo que inibe a conversão das vivências em experiências, as personagens de Handke tentam desesperadamente transformar pequenos detalhes de uma série de ações em grandes acontecimentos. Do passado, o narrador de Breve carta não guarda senão imagens fragmentadas. Falta-lhe o conhecimento e a experiência advindos de suas vivências. Acumula-se experiência, no sentido proposto por Benjamin, à medida em que um fato vivenciado no passado interfere nas vivências presentes e futuras. No caso de Breve carta, a vivência, já perdida, será substituída pela memória como requisito para o acesso ao conhecimento e experiência de si e do mundo, processo esse que será intensificado na viagem empreendida pelo narrador, metáfora de sua viagem interior. A dolorosa, mas necessária, ruptura com o passado opera por intermédio de um trabalho íntimo, interior, de rememoração da própria identidade.

Vivendo em um mundo saturado de imagens, o narrador de Breve carta aprende, então, que a visão também pode liberar ao invés de simplesmente perturbar o indivíduo: ver passa a ser sinônimo de compreender. Para tanto, o cinema aparece como adjuvante no processo que leva à compreensão de si e do real.

Ao assistir a um filme de Tarzan, com Johnny Weissmüller, o narrador é tomado, em um primeiro momento, pela sensação de ver algo proibido, mas já anteriormente imaginado, "as imagens evocando algum sonho esquecido" (p. 94).Pouco a pouco, as recordações se consolidam à medida que as imagens são projetadas na tela de cinema, e o narrador percebe que esse "sonho esquecido" nada mais era senão as imagens do próprio filme, assistido quando criança, agora retornando de forma difusa e adiantandose às cenas que o filme projetava.

Se, para Proust, o processo de apropriação do real baseava-se na vivificação da memória pelos sentidos do olfato (o perfume dos lilases e dos pilriteiros), da audição (os sinos de Martinville, a sonata de Vinteuil), mas, sobretudo, do paladar (a madeleine), reavivando e atualizando momentos do passado, em Handke cabe às imagens tecnológicas (o cinema e seus derivados) o papel de desencadeadoras da memória nos indivíduos filhos da "civilização da imagem". As imagens fílmicas agem no espectador enquanto catalisadoras dos processos mentais "adormecidos" em algum lugar do inconsciente humano e ajudam na revitalização de um presente que depende da memória para a compreensão do mundo.

Em outros momentos, a imagem de um velho filme pode, de súbito, assaltar o narrador, sem que seja necessária a visão do filme projetado na tela do cinema. Novamente, a imagem da memória precede a imagem fílmica e não necessariamente depende da visão, pois o filme desenrola-se na tela interior do sujeito. Assim, a imagem de The Iron Horse, de John Ford, ocorre ao narrador de Breve carta enquanto esse caminha e escuta o andar 
de Claire atrás de si, sendo tomado por uma angústia que se reflete em seu corpo ao assistir à seqüência do filme em sua mente:

Sem que pudesse explicar, eu me sentira mal assistindo ao filme, sentia uma dor repuxando meu peito, impulso de engolir, um sofrimento, como se ferido, a pele toda sensível, quase um calafrio. (p. 136)

O efeito anestésico do bombardeio imagético a que o indivíduo é exposto oprime e atordoa seus sentidos, impede a consciência de sonhar e torna o mundo inapreensível. Progressivamente, no entanto, o narrador de Breve carta passa a extrair outras experiências das imagens, e o cinema surge como atalho para o sonho:

$\mathrm{Eu}$, em geral, tinha vontade de sair dos cinemas e lá fora respirava aliviado. Olhar coisas determinadas me cansava, o ritmo das imagens me oprimia, e me doía respirar. Só uma vez, quando assisti com o casal de amantes ao Young Mr. Lincoln, de John Ford [...] esqueci-me, e olhar o filme tornou-se ao mesmo tempo sonhar. (p. 159)

Do mesmo modo, a obsessão pelos filmes de John Ford não é fortuita. Assim como para o narrador, para Ford sempre fora difícil falar de suas experiências, preferindo, portanto, falar daquilo que os outros viveram antes dele, no caso histórias da América. "Contador de histórias" americanas através de um meio de reprodução industrial, Ford articula, por intermédio das imagens, história e memória. Para o narrador de Breve carta, os filmes do diretor americano são fonte de uma aprendizagem que, como a sua, depende da apropriação consciente e criativa do material icônico que o circunda, o que o leva a visitá-lo ao final do romance.

Finalmente, Breve carta para um longo adeus parece ilustrar com perfeição o já aludido texto de Italo Calvino sobre a visibilidade como um dos seis valores a serem preservados em nosso milênio. Segundo Calvino, na chamada "civilização da imagem", corremos o risco de perder a capacidade de sonhar de olhos fechados, de construir cores e formas a partir dos caracteres impressos no branco da página, enfim, de pensar por imagens. Com essa preocupação, propõe uma espécie de "pedagogia da imaginação", capaz de controlar a própria visão interior sem sufocá-la e sem, por outro lado, "deixá-la cair num confuso e passageiro fantasiar, mas permitindo que as imagens se cristalizem numa forma bem definida, memorável, auto-suficiente". ${ }^{8}$ Trata-se, é claro, de uma pedagogia que somente pode ser aplicada a nós mesmos, exercício individual e subjetivo que visa à retomada de consciências e memórias cada vez mais distantes, em vias de se perderem em meio ao aparato tecnológico reprodutor de imagens. Estamos aqui perante a necessidade de recuperar as dimensões mágicas da imaginação e, em última análise, da própria capacidade de sonhar.

É, portanto, nesse sentido que o herói do romance contemporâneo passa a experimentar um fascínio alucinante frente às imagens que diariamente o assaltam a ponto de não mais distingui-las da realidade, "apresentando-se-lhe esta última como um pálido ersatz do universo icônico aureolado de imaginário fantasmático". ${ }^{9}$ Os dois universos - real e

${ }^{8}$ CALVINO. Seis propostas para o próximo milênio, p. 108.

${ }^{9}$ CLERC. A literatura comparada face às imagens modernas: cinema, fotografia, televisão, p. 311 . 
imagético - interpenetram-se constantemente, fazendo com que a imagem dificulte, muitas vezes, a apreensão do real. Por outro lado, a fotografia, o cinema, os anúncios publicitários e, mais tarde, a televisão e a internet, acabam por fornecer ao romance um rico material temático, ao mesmo tempo em que revelam "o reflexo que uma sociedade dá de si mesma por intermédio das imagens que fabrica e, mais profundamente, das grandes questões que se colocam sobre a realidade". ${ }^{10}$

\section{A}

\section{RÉ S U MÉ}

Cet article a pour but de repérer quelques-unes des catégories de l'imaginaire visuel contemporain, notamment l'imaginaire du cinéma, qui imprègnent le texte littéraire dans le cadre d'une culture profondément liée aux technologies des images industrielles. A titre d'exemple, on prend comme corpus d'analyse le roman Der kurze Brief zum langen Abschied, de l'autrichien Peter Handke.

\section{MOTS - CLÉS}

Fiction contemporaine, culture médiale, l'imaginaire cinématographique, visibilité

\section{REFERÊNCIAS}

BENJAMIN, Walter. A obra de arte na era de sua reprodutibilidade técnica. 1936. In: BENJAMIN, W. Magia e técnica, arte e política. Trad. Sergio Rouanet. São Paulo: Brasiliense, 1985.

CALVINO, Italo. Seis propostas para o próximo milênio. Trad. Ivo Barroso. São Paulo: Companhia das Letras, 2002.

CLERC, Jeanne-Marie. A literatura comparada face às imagens modernas: cinema, fotografia, televisão. In: BRUNEL, Pierre; CHEVREL, Yves (Org.). Compêndio de literatura comparada. Trad. Maria do Rosário Monteiro. Lisboa: Fundação Calouste Gulbenkian, 2004.

DELEUZE, Gilles. Cinéma II: Limage-temps. Paris: Minuit, 1985.

GUIMARÃES, César. Imagens da memória: entre o legível e o visível. Belo Horizonte: Editora da UFMG, 1997.

HANDKE, Peter. A mulher canhota e Breve carta para um longo adeus. (1972.) Trad. Lya Luft. São Paulo: Brasiliense, 1985.

JAMESON, Fredric. Espaço e imagem: teorias do pós-moderno e outros ensaios. Trad. Ana Lúcia Almeida Gazolla. Rio de Janeiro: Editora da UFRJ, 1995.

VISWANATHAN, Jacqueline. L'imaginaire du cinéma dans trois romans québécois. In: Africa - America - Asia - Australia. n. 20. Littérature et cinéma du Québec. Atti del Convegno di Bologna. Roma: Bulzoni Editore, 1997.

${ }^{10}$ CLERC. A literatura comparada face às imagens modernas: cinema, fotografia, televisão, p. 311. 